\title{
ERROS E OBSTÁCULOS: OS CONTEÚDOS MATEMÁTICOS DO ENSINO FUNDAMENTAL NO PROCESSO DE AVALIAÇÃO ${ }^{1}$
}

\author{
Weverton MIRANDA \\ Secretaria de Estado de Educação e Cultura/PA \\ wesamiranda@yahoo.com.br
}

\begin{abstract}
Resumo: $O$ presente artigo tem como primeiro objetivo refletir, de forma a articular, os conceitos de 'avaliação', 'obstáculo' e 'erro', implicando as definições e as relações que entendemos existir entre esses como grandes temas, tendo em vista evidenciar que erros se constituem em 'obstáculos didáticos' para a aprendizagem de matemática no ensino fundamental. Além disso, objetivamos analisar o desempenho de alunos de $5^{a}$ a $8^{a}$ séries na disciplina Matemática para elaborar uma lista de conteúdos matemáticos que suscitam maiores dificuldades de assimilação no processo de ensinoaprendizagem desses estudantes. Os resultados nos mostram que quando um conteúdo não foi bem assimilado pelo aluno pode vir a se constituir como 'obstáculo didático' para a aprendizagem matemática, de forma tal que influencia negativamente a aprendizagem posterior uma vez que tende a se propagar pelas séries subsequentes.
\end{abstract}

Palavras-chaves: Ensino de Matemática. Aprendizagem de Matemática. Obstáculos Didáticos.

Abstract: The present article aims to focus certain ways to articulate the
mathematical concepts 'evaluation', 'obstacle' and 'error' based upon the definitions
and relations we find between these issues, while considering that some mathematical
errors come to constitute 'didactic obstacles' for mathematics learning. Besides this
we intend to analyze the teachers' fulfillments from 5th to 8th grades in math usual
subject becoming possible to make a list of contents that constitutes great difficulties for
the students' assimilation in math teaching-learning processes. The results we find
show us that when the content wasn't well assimilated by the student it can emerge
as 'didactic obstacles' for mathematics learning and tends to propagate through the
posterior schooling grades.

Keywords: Mathematics Teaching. Mathematics Learning. Didactics Obstacles.

\footnotetext{
${ }^{1}$ Este artigo é resultante de parte da dissertação de Mestrado, de mesmo título, apresentada e defendida em 2007, no Programa de Pós-Graduação em Educação em Ciências e Matemáticas da Universidade Federal do Pará/ UFPA.
} 


\section{Introdução}

No presente artigo temos o propósito de refletir sobre as formas de articular os conceitos de 'avaliação', 'obstáculo' $e$ 'erro', implicando as definições e as relações que entendemos existir entre tais conceitos como grandes temas dos processos de ensino e de aprendizagem de matemática.

Além disso, para evidenciar as premissas postas, objetivamos analisar o desempenho de alunos de $5^{\mathrm{a}}$ a $8^{\mathrm{a}}$ séries na disciplina Matemática, para elaborar uma lista de conteúdos matemáticos que trazem grandes dificuldades de assimilação para os alunos no curso do processo de ensino-aprendizagem. Para isso, tomamos como parâmetro de análise e diferenciação das ideias de 'erro' - erro em si ou "erro passageiro" e erro que indica um obstáculo didático - as questões que apresentam um quantitativo de erros semelhantes com o índice de $20 \%$ ou mais do total de estudantes na turma especificada. Neste sentido, tivemos como guia de pesquisa, a intenção de verificar quais erros dentre os que vêm ocorrendo na aprendizagem dos nossos estudantes, estão se constituindo como obstáculos didáticos para a aprendizagem dos conceitos matemáticos de $5^{\mathrm{a}}$ a $8^{\mathrm{a}}$ séries.

\section{Uma corda de três fios: avaliação, obstáculo, erro}

\subsection{Avaliação}

Numa abordagem geral já é difícil discorrer sobre a avaliação, muito mais o é quando esta se situa no âmbito de processos de ensino e de aprendizagem. Isto porque a ação pedagógica é uma atividade planejada que insere caracteres individuais e coletivos, dentre os quais, a avaliação que se faz presente de forma imperativa por constituir-se em um elemento multifuncional, desde o planejamento até o que a caracteriza como "encerramento" do ato educativo. É por essa multifuncionalidade que inúmeros autores se dedicam a estudar e escrever sobre tal tema, principalmente para descrever como tem sido usada e como deveria ser praticada a 'avaliação da aprendizagem do aluno'. 
No tempo presente, tem sido enfatizado que a avaliação da aprendizagem do aluno evidencia nossa concepção de ensino, nossa visão de mundo e nosso comprometimento social. Sendo assim, ela é, em última análise, um instrumento de manifestação político-ideológica do fazer pedagógico de cada um de nós como professores-educadores.

A fim de nos auxiliar na tentativa de responder o que vem a ser uma avaliação, Romão faz comentários sobre uma série de definições cunhadas pelos mais renomados autores do assunto em pauta, autores e definições tais como as de Bradfield \& Moredock que assim se expressam: "Avaliação é o processo de atribuição de símbolos a fenômenos com o objetivo de caracterizar o valor do fenômeno, geralmente com referência a algum padrão de natureza social, cultural ou científica" (BRADFIELD; MOREDOCK, 1963, p. 1-16). Enfoca também a de Luckesi, que resume ser a avaliação "um juízo de qualidade sobre dados relevantes para uma tomada de decisão" (LUCKESI, 1995, p. 9).

Fazendo uma síntese desses autores e de outros como Haydt (1988), Sousa (1993) e Sant'anna (1995), também citados por Romão (1998), atrevo-me a dizer que a avaliação escolar é um instrumento de levantamento de dados quantitativos/qualitativos do processo de aquisiz̧ão/manifestação de conhecimento por parte do aluno.

São inúmeras as referências que os diversos autores utilizam para expressarem tanto suas críticas quanto perspectivas em relação à função e à forma de realização da avaliação do processo de ensino e de aprendizagem. Porém, nas entrelinhas do que é posto ou proposto, sempre encontramos formas usuais de avaliação quais sejam: a avaliação diagnóstica, a avaliação formativa e a avaliação classificatória.

A avaliação diagnóstica é aquela que se destina a levantar informações sobre os conhecimentos que os estudantes já possuem em relação a um determinado assunto ou a um conjunto de conhecimentos, os quais são considerados indispensáveis para a adequada aprendizagem de outros; sendo fundamental para a tomada de decisão em relação a por onde e como iniciar um curso, unidade ou abordagem de um tema específico e orientar a escolha das estratégias metodológicas que favoreçam o alcance dos novos objetivos. 
A avaliação formativa objetiva o levantamento de informações sobre o desempenho de cada aluno-e da classe simultaneamente-, durante o processo de ensino-aprendizagem, tendo em vista o acompanhamento contínuo da aquisição do conhecimento desses aprendizes. Didaticamente falando, é o acompanhamento do grupo de aprendizes em uma dinâmica individualizada. A avaliação formativa, portanto, diz respeito ao sujeito comparado com ele mesmo.

$\mathrm{Na}$ avaliação classificatória se faz juízos de valor sobre o processo ocorrido, materializando-o, no processo escolar, no resultado final de um período de aprendizagem, expressando-os em uma forma binária - aprovação ou reprovação; por isso esta é também conhecida como avaliação somativa. Esta forma é frequentemente utilizada nos processos de seleção; não apenas nas instituições educacionais, mas em todos os setores da sociedade, como instrumento político de seleção e controle da mobilidade de classes sociais (VASCONCELLOS, 1998).

Sendo assim, os autores tendem a levantar dúvidas sobre o que se pratica nas escolas em termos de avaliação, buscando auxiliar professores e estudantes na tomada de consciência sobre o percurso já realizado e a distância para atingir os objetivos, os impedimentos existentes e as melhores formas de superá-los.

\subsection{Obstáculo}

Partindo dos significados de senso comum de 'obstáculo' como impedimento e obstrução, podemos entender a definição de obstáculo epistemológico de Bachelard (1996) ${ }^{2}$, quando se refere às dificuldades da Ciência ao longo da História. Para este filósofo, o obstáculo epistemológico é constituído de um conhecimento já adquirido que faz resistência a um conhecimento novo. Isto porque o conhecimento existente contém erros que impedem conhecer o real, pois o real nunca é 'o que se poderia achar', mas é 'o que se deveria ter pensado'. São suas as considerações seguintes:

${ }^{2}$ A primeira edição foi publicada em 1938. 
E não se trata de considerar obstáculo externo, como a complexidade e a fugacidade dos fenômenos, nem de incriminar a fragilidade dos sentidos e do espírito humano: é no âmago do próprio ato de conhecer que aparecem, por uma espécie de imperativo formal, lentidóes e conflitos. É aí que mostraremos causas de inércia às quais daremos o nome de obstáculo epistemológico (BACHELARD, 1996, p. 17).

Tendo por base a concepção de 'obstáculo epistemológico' de Bachelard, Brousseau (1976, apud BITTENCOURT, 1998) transcende tal concepção para a dimensão didática e relaciona três obstáculos conforme a origem observada, quais sejam: Ontogenética, referente ao desenvolvimento cognitivo considerando os trabalhos de Piaget e outros; Didática, que decorre das escolhas de estratégias de ensino; e Epistemológica, que diz respeito à resistência ao conhecimento propriamente dito, conforme a concepção bachelardiana.

Outros autores, como Almouloud (2006), apontam a existência de obstáculos linguísticos que se referem às barreiras de linguagem que impedem a compreensão do conteúdo em função da não habilidade no uso da língua materna, por parte de aprendizes, e até de professores que utilizam os mesmos significantes com significados diferentes. E Gusmão (2000) traz ao nosso conhecimento os obstáculos emocionais que advêm da manifestação de alteração da nossa estabilidade emocional e que, diante de determinadas tarefas e disciplinas, podem induzir ao erro.

De todos os obstáculos até aqui citados, é relevante nos debruçarmos sobre os obstáculos que ocorrem com mais visibilidade no meio educacional que, segundo Almouloud (2006), resultam de opção metodológica do professor ou de livros, com o objetivo de apresentar e discutir os conteúdos, gerando conhecimentos incompletos ou equivocados.

Podemos, pois, inferir que os 'obstáculos didáticos' surgem no âmbito do planejamento (ou na falta deste) do trabalho a ser realizado em sala de aula, e também é o planejamento o espaço privilegiado para a busca de sua superação. Sendo assim, os obstáculos didáticos congregam em seu entorno todos os outros obstáculos anteriormente listados, pois como define propriamente Pais (2001), os obstáculos didáticos são conhecimentos relativamente estabilizados no plano intelectual, dificultando a evolução da aprendizagem do saber escolar. Além deste 
autor, Bittencourt (1998) nos informa que a ausência de resposta do aluno acaba sendo um tipo de 'obstáculo didático', visto que ignorar um problema, demonstrar incapacidade de resolvê-lo, rejeitá-lo e até desconsiderar seu caráter problemático também são atitudes reveladoras de obstáculo.

Embora caminhemos para sete décadas do surgimento da expressão 'obstáculo didático', não encontramos na literatura pesquisada registros sobre o que caracteriza efetivamente um obstáculo didático e como estudá-lo. O que temos é referência clara sobre a íntima relação entre a existência de erros e obstáculos e a emergência de obstáculos didáticos. Considerando essa relação, podemos inferir que estudar 'obstáculos didáticos' é estudar 'a existência quantitativa e qualitativa de erros observáveis no desenvolvimento escolar dos estudantes'.

\subsection{Erro}

Historicamente, o erro é estigmatizado como indicador de imperícia e incapacidade. No âmbito escolar, o "erro é sempre a constatação de um déficit na aprendizagem", sendo visto "como 'um vírus a ser eliminado' e, desse modo, sempre indesejado" (PINTO, 2000, p. 20). Para eliminar erros, os castigos físicos atrelados à exposição pública foram, segundo Luckesi (2002), os mecanismos mais utilizados.

No presente, Vasconcellos (1998) indica que o erro através da avaliação é utilizado como instrumento de seleção social mantendo, por isso, a primazia dos dominantes sobre os dominados. Nesse sentido, a ascensão social via escola é, ao mesmo tempo, estimulada a todos e negada à maioria pela super valorização do acerto e depreciação do erro, sem considerar a natureza do processo de aprendizagem.

$\mathrm{Na}$ literatura disponível sobre erros na atualidade, vemos que há indissociabilidade entre a concepção de erro e de avaliação, ficando evidente que, se o caráter da avaliação é classificatório, o erro será considerado de forma negativa, influenciando diretamente na promoção escolar. Contudo, se o aspecto mais importante da avaliação for a formação de conceitos do aluno, for a sua independência intelectual que implica aprendizagem efetiva, a existência do erro será vista positivamente. Isso perpassa, como ressalta Pinto (2000), pela concepção que o professor tem 
da disciplina que leciona, uma vez que, como diz este autor, toda concepção de erro encontra-se atrelada à concepção do próprio professor sobre sua disciplina, a forma de conceber o processo de ensino-aprendizagem e, conseqüentemente, os modos de praticar a avaliação.

Os diversos autores - que se propõem a dissertar sobre a existência do erro no âmbito do processo de aprendizagem - deixam transparecer em seus textos que o erro é algo sempre presente no cotidiano humano, independente de idade, atividade e posição social, tanto que sua definição torna-se desnecessária. Assim, falar de erro é expressar-se sobre algo universal e ao mesmo tempo impregnado de subjetividade, cuja definição fica a cargo de nossa memória afetiva formada ao longo de nossa vivência humana. Por isso, os autores nos deixam a sensação de que 'saber o que é o erro é saber o que é certo', já que o erro apresenta-se com uma autodefinição por antagonismo, e curiosamente o mesmo acontece com o seu antagônico - o 'certo/acerto'-, constituindo-se nas duas faces de uma mesma moeda, o fazer humano e, mui especialmente, no ato de aprender e ensinar - o 'processo de ensinoapredizagem'.

Depresbiteres (1995), quando comenta sobre 'erros', nos informa que esses podem ser favorecidos pela escola, pois há estudantes que apresentam competência linguística ou matemática, no seu dia-a-dia, fora da escola, e mesmo assim chegam ao fracasso escolar. Em um outro momento, a mesma autora, ao comentar as ideias de Davis (1990), nos lembra que é tarefa do professor distinguir os erros dos educandos e torná-los observáveis aos mesmos para que tomem consciência deles, contribuindo para que o erro seja superado sem punições. Da mesma forma, Pinto (2000) refere-se ao 'erro' como um divisor de águas de duas tendências fortes em educação, quando faz alusão à Pedagogia Tradicional em contraposição à Pedagogia Nova, cuja preocupação para essa ultima é saber como o estudante aprende e o erro é um conhecimento que mostra o caminho do acerto que já está ali implícito.

Podemos dizer que, em termos gerais, ERRO é o desvio em relação ao padrão ou ideal preestabelecido. Nessa mesma perspectiva, Gotino, Batanero \& Font (apud POCHULU, 2005) nos dizem que, em matemática, falamos de erro quando o estudante realiza uma prática (ação, argumentação, etc.) que não é válida do ponto de vista da instrução da matemática escolar. 


\section{Entrelaçando os fios}

\subsection{Relação entre 'erro e avaliação'}

O estudo do erro em qualquer disciplina pode contribuir para tornar a avaliação mais produtiva em suas funções diagnóstica e formativa, nos processos de ensino e de aprendizagem, tendo como consequência a facilitação da aquisição de conhecimentos - e especialmente em Matemática - para a desmistificação de seu ensino.

O erro é sempre revelador do que está ocorrendo em qualquer processo. Nesse sentido, considero que o estudo sobre erros em Matemática contribui para: (a) Diagnosticar dificuldades de aprendizagem, em termos quantitativos, na relação entre o domínio de conhecimento objetivado pelo professor e o domínio demonstrado pelos estudantes, sublinhando em cada erro o que estes já sabem e o que "falta" saber em relação ao preestabelecido; (b) Mostrar o desenvolvimento cognitivo dos estudantes, tendo em vista que cada conteúdo e grau de dificuldade a este relacionado possuem ligação com nossas estruturas psicológicas; (c) Evidenciar o desenvolvimento da aprendizagem individual do educando; (d) Indicar como está ocorrendo o processo de ensino-aprendizagem na turma; (e) Apontar indícios de obstáculos no processo e auxiliar na tomada de decisão sobre a metodologia; ( $\mathrm{f}$ ) Revelar indícios de obstáculos didáticos ao evidenciar que determinados procedimentos ou resultados são comuns em uma ou mais turmas, embora não seja aquilo que é "tido como certo"; (g) Abrir espaço para a reflexão docente quanto aos seus próprios erros e obstáculos e quanto à influência desses na formação dos erros e obstáculos didáticos dos estudantes.

Assim, o estudo do erro não se limita a identificá-los através da comparação das respostas dadas com o padrão esperado, mas visa buscar suas possíveis causas, considerando, para isso, os conhecimentos que cada erro manifesta e a "distorção" em relação ao conhecimento esperado, sendo vistos, pois, como elementos que indicam os fatores que obstaculizam o aprendizado da matemática. Nestes termos, procuramos não só perceber a maneira pela qual cada estudante constrói sua linha de raciocínio, buscando pistas nas respostas dadas em seus rascunhos; mas também evidenciar as 
semelhanças entre os erros detectados; o que "reformula" o nosso papel docente no qual "o professor não deverá apenas fazer suposições sobre a lógica dos estudantes, mas, para que possa guiar o desenvolvimento de suas idéias, é importante que saiba o que os estudantes pensam no momento da aprendizagem" (PINTO, 2000, p. 35).

Concordamos com a autora referida uma vez que consideramos possível o estudo dos erros dos estudantes na disciplina Matemática em dois níveis: (a) Nível Individual - no qual a atenção sobre os erros de um aprendiz busca a relação de conhecimentos manifestos e ausentes entre dois ou mais erros detectados, o que dará subsídio para auxiliar na superação das dificuldades; (b) Nível Coletivo - no qual se "mapeiam" todos os conhecimentos manifestos e ausentes em cada erro identificado.

Neste contexto, o estudo qualitativo do erro não descarta a quantificação, porém esta é vista como indicador de obstáculos didáticos, já que uma de suas características é a manifestação de um mesmo erro por considerável número de alunos (obstáculo coletivo), ou a repetição sistemática de um erro pelo mesmo aprendiz em diferentes ocasiões (obstáculo individual).

\subsection{Relação entre erro e obstáculo didático}

É escassa, na literatura educacional brasileira, a abordagem de 'erros' cometidos por estudantes durante o processo de ensinoaprendizagem, as publicações sobre possiveis 'obstáculos didáticos', bem como sobre a relação entre eles. Porém, existe um certo consenso entre os autores que tratam desse tema em diversos países, qual seja: o erro é um indicador de existência de obstáculos didáticos, pois aquele é muitas vezes "fruto" destes. Nestes termos, Bittencurt (1998) se pronuncia sobre o trabalho de Brousseau dizendo que este autor, em sua pesquisa relativa ao ensino dos números decimais, analisa diversos obstáculos tanto didáticos quanto epistemológicos, considerando-os como fontes de erros futuros do estudante. Da mesma forma, Cury (1995), credita a Brousseau a afirmação de que um obstáculo se manifesta por erros.

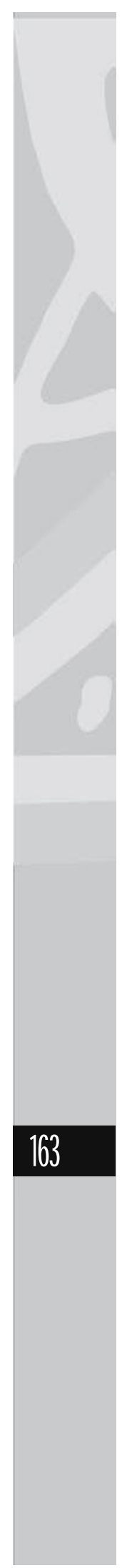


Entretanto, há autores, como El Bouazzoui (ApudCURY, 1995), que nos alertam para a necessidade de diferenciar entre 'erros', 'dificuldades' e 'obstáculos'; mas é justamente Bittencurt quem mais contribui com informações para evidenciar esta relação ao afirmar o seguinte:

\begin{abstract}
A noção de obstáculo epistemológico concede ao erro um papel importante enquanto revelador de dificuldades a serem seriamente consideradas por aquele que pretende compreender melhor o processo cognitivo. [...] O erro do estudante revela a maneira como este organiza seus conhecimentos, geralmente agrupados em torno de concepcões e valores formando uma rede de significados que muitas vezes torna-se um obstáculo à aquisição de novos conceitos (BITTENCOURT, 1998, p, 15 - grifos nossos).
\end{abstract}

Podemos observar, pelas contribuições dos autores referidos, que a relação entre 'erro' e 'obstáculo didático' é considerada intrínseca, sendo difícil determinar, entre os dois, aquele que origina o outro, pois tanto o erro faz surgir obstáculo didático, quanto o obstáculo didático causa erro.

Quando um erro é cometido por personagens que, no imaginário social, gozam de um certo status de "autoridade inquestionável", como renomados cientistas ou membros da igreja católica, por exemplo, - esta por muito tempo se opôs à teoria heliocêntrica do universo -, esses casos são registrados na história, mas mesmo depois de "corrigidos" ainda têm seus conceitos anteriores considerados válidos, sendo empecilhos no ensino e na aprendizagem. A isso também consideramos e chamamos de 'obstáculos didáticos' que são constituídos por 'erros'.

Por outro lado, como assinalamos, obstáculos didáticos nos remetem a erros. Um bom exemplo disso é a concepção de sinal unicamente como símbolo de operação. Quando estamos envolvidos no processo de ensino-aprendizagem de assuntos, tais como equações, a maioria de nós, professores de matemática, na tentativa de facilitar a compreensão dos nossos alunos, nos expressamos assim: - quando um termo é passado para o outro membro (outro lado da igualdade) ele troca de sinal.

Tal discurso contribui para se criar ou estabelecer alguns obstáculos didáticos, como ter, respectivamente, os sinais "+" e "-" apenas como indicadores de soma e subtração e não como indicadores de posição relativa na representação geométrica da reta numérica; o "X" não é 
visto como incógnita da equação e sim como indicador de produto; não reconhecendo outras formas de indicar essa operação $(\bullet$, ou ausência de sinal entre o número e a variável, ou entre variáveis, etc.) e divisão (:, o traço de fração, etc.); comprovando a posição de Almouloud (2006), que aponta o 'obstáculo linguístico' como um dos fatores que contribuem para o surgimento de obstáculos didáticos.

Portanto, nossa ação de professores de matemática, que éoportunizar aos estudantes a aquisição de conhecimentos passando pela superação dos seus erros durante seu processo de aprendizagem, aponta para o desafio de mudar a postura que temos diante do erro, passando a (i) vê-lo como manifestação de um certo tipo de conhecimento, (ii) distingui-lo enquanto fruto de dificuldades momentâneas e (iii) compreendê-lo como um tipo de resistência de um conhecimento existente no aluno ao conhecimento novo, certamente estabelecido por um obstáculo didático.

\subsection{Relação entre obstáculo didático e avaliação}

Retomando as definições e classificações formuladas por diversos autores sobre 'avaliação' e 'obstáculo', podemos vislumbrar a aproximação existente entre 'obstáculo didático' e 'avaliação da aprendizagem', pois é através do ato avaliativo que: (a) identificam-se as respostas insatisfatórias que chamamos de 'erros', (b) classificamos os 'erros' entre "erros passageiros" - como expressão para denotar as respostas insatisfatórias fruto de pressa, desatenção, etc. que ocorrem, mas se o estudante revisasse sua resposta certamente detectaria a falha - e "obstáculos" - que categorizamos como 'obstáculos epistemológicos', 'obstáculos ontongenéticos' e 'obstáculos didáticos'. Torna-se inevitável a percepção da interface existente entre 'obstáculos didáticos' e 'avaliação', quando esta passa a ser um instrumento efetivo de investigação educacional, traduzindo-se na melhoria do processo ensinoaprendizagem em Matemática. É através da avaliação que podemos distinguir as diversas facetas dos obstáculos didáticos que, segundo Almouloud (2006), tem em suas variáveis principalmente a linguagem e a metodologia.

Por isso, como Desprebiteres (1995) propõe claramente, a avaliação da aprendizagem deve auxiliar na busca de respostas para essas questões, visando à análise do produto e do processo da aprendizagem. Isto quer dizer que a relação entre 'obstáculo didático' e 'avaliação' está justamente 
no fato desta última se constituir um instrumento teórico-prático que possibilita não só a identificação de obstáculos didáticos, mas das relações de conhecimento que os constituem, abrindo um espaço de reflexão sobre o processo de aprendizagem, sobre a origem dos 'erros' e 'obstáculos', e por fim, sobre um planejamento de ensino que auxilie os estudantes a superá-los, traduzindo-se na melhoria do processo de aprendizagem da matemática.

Sob estaótica, podemos dizer que a avaliação pode auxiliaro professor e demais agentes educacionais a: i) Diferenciar "erros passageiros" de 'obstáculos didáticos'; ii) Identificar e mapear os obstáculos didáticos em relação a cada assunto, e iii) Buscar a superação desses obstáculos didáticos, dando maior atenção aos assuntos que obstaculizam a aprendizagem de outros assuntos da disciplina.

Em todo processo de ensino e aprendizagem significativos, o aprendizado de assuntos anteriores é relevante para o aprendizado do assunto eleito para aquele determinado momento de aprendizagem em que o aluno se encontra. $\mathrm{Na}$ educação matemática isso parece ainda mais destacado, principalmente por que professores e estudantes sempre parafraseiam um provérbio, dizendo que em Matemática "são as águas passadas quem movem os moinhos". Assim sendo, analogicamente, os "erros sistemáticos" - individuais ou coletivos - emperram (obstaculizam) o moinho da aprendizagem que impulsiona os ventos do conhecimento.

\section{Delimitando o espaço da pesquisa}

A pesquisa, aqui desenvolvida, teve por propósito estudar o desempenho dos estudantes de $5^{\mathrm{a}}$ a $8^{\mathrm{a}}$ séries, na disciplina Matemática, utilizando as respostas dadas por eles como alunos de uma escola pública de Ensino Fundamental, na cidade de Belém do Pará. Estes sujeitos foram participantes de um projeto piloto que visava fornecer auxílio teóricometodológico a aprendizes com dificuldades em Matemática, fazendo um tipo de recuperação paralela diferenciada. Para tanto, foi elaborado um teste que abordava o conteúdo da série em questão, concomitantemente, com alguns conteúdos específicos ensinados/estudados em séries anteriores.

Assim, algumas questões são comuns a todas as séries, possibilitando fazer um quadro geral de análise sobre o desempenho dos estudantes 
em relação à forma de mobilizar os conhecimentos dos conteúdos "aprendidos" ao longo de sua escolaridade, principalmente nas quatro séries finais do ensino fundamental. Essas análises têm o intuito de: I) Identificar erros que se manifestam sistematicamente em cada série; II) Observar a trajetória de incidência dos erros nos quatro anos finais do ensino fundamental e sua possível superação; III) Tentar buscar, na análise dos erros dos alunos, os elementos que indiquem os fatores que obstaculizam o aprendizado da Matemática de $5^{\mathrm{a}}$ a $8^{\mathrm{a}}$ séries.

Para nós, o grande desafio foi identificar a tênue linha que delimita a faixa de intersecção entre os erros e os obstáculos didáticos; com esse entendimento, tomamos como parâmetro para a análise e a diferenciação entre "erro passageiro" e "erro que indica um obstáculo didático", os erros semelhantes com índice igual ou superior a $20 \%$ do total da turma.

Embora este percentual expresse uma escolha arbitrária, cremos que os $20 \%$ se justificam pelas seguintes razões: a) Sempre que nos referimos a rendimento escolar, consideramos satisfatório o aproveitamento igual ou superior a $80 \%$, geralmente associado a notas acima de 8,0 (oito inteiros), dando uma margem de $20 \%$ para as manifestações das imperfeições naturais, já que "errar é humano"; b) Também devemos ter em consideração que o ideário educativo implica "zerar a incidência de erro", por isso não podemos aceitar passivamente que metade de uma turma (ou uma taxa próxima) não corresponda ao desempenho esperado como algo normal, e c) Em outras ciências, ou em outros tipos de pesquisa, raramente se admite uma margem de erros/perda desta magnitude.

Por todos esses motivos, acreditamos que a percentagem considerada representa o máximo de tolerância que podemos ter diante dos erros de uma turma sem desconfiar que algo esteja inviabilizando o processo.

\section{Resultados da Pesquisa}

Fazendo uma análise geral dos erros relacionados nas quatro séries do segundo ciclo do ensino fundamental, chegamos à constatação de que há uma maior variedade de erros entre nossos estudantes do que aquela descrita por Pochulu (2005), cuja lista de erros na perspectiva dos professores do ensino fundamental continha 18 itens. Isto talvez tenha se dado porque o autor relacionou os erros justamente da perspectiva dos 
professores, os quais sintetizaram distorções semelhantes. De outra forma, a presente pesquisa teve como fontes as respostas cunhadas pelos estudantes. Mesmo assim, onze dos dezoito erros relacionados pelo autor referido, como característicos das séries finais do nível fundamental de ensino, coincidem com os erros apresentados pelos sujeitos da nossa pesquisa. Destacamos, ainda, que todos os erros referentes aos 'Números Racionais' são comuns entre a lista do autor considerado e a nossa amostra pesquisada, podendo significar um relevante obstáculo didático de âmbito coletivo se forem expressos - conforme explicitamos na metodologia - com um índice de erro igual ou superior a $20 \%$, hipótese que será subsequentemente estudada.

Alguns dos erros listados por Pochulu (2005) não figuram entre os erros dos estudantes da amostra por nós analisada. Isto principalmente se deu, é necessário destacar, porque os testes utilizados na nossa pesquisa não abordaram os assuntos a que o autor faz referência, a saber: erram na aplicação das regras de sinais da multiplicação ao efetuar soma com números inteiros (Erro 1); Aplicam a propriedade distributiva da radiciação em operações de soma ou subtração (Erro 10); estimam que a raiz com radicando negativo e índice ímpar tem duplo resultado, ou que não possui solução no conjunto dos reais (Erro 11); decodificam incorretamente os valores representados por letras em uma reta numérica (Erro 12); não identificam as figuras geométricas elementares quando em posição "não estudada" (Erro 16); supõem que a altura de um triângulo é sempre um segmento interior à figura (Erro 17); truncam respostas que procedem das unidades de medida em problemas que envolvem magnitudes (Erro 18). Em contrapartida, fazendo uma síntese das variações de respostas dos participantes de nossa pesquisa, encontramos 41 erros diferentes dos listados por Pochulu (2005).

As questões que foram comuns a todas as séries nos permitem acompanhar longitudinalmente: (a) a existência de obstáculos didáticos, bem como (b) sua propagação ou superação ao longo da escolaridade. Para ilustrar essa verificação, destacamos dois dos obstáculos comuns às séries pesquisadas, sendo eles: a multiplicação de 20,17 por 10 , onde temos como erro o não deslocamento da vírgula, colocada na mesma posição ou suprimida; e a subtração de 2,7 por 1,28 , configura-se como obstáculo didático o fato de inverterem o minuendo para subtraendo e tentarem subtrair, tendo por critério que $8>7$. 
O primeiro tipo de erro, acima descrito, esteve presente como obstáculo na $5^{\mathrm{a}}$ série, com índice de $42,85 \%$, não se fazendo presente na $6^{a}$ nem na $7^{a}$ séries, retornando à $8^{a}$ série com uma redução de 9,52 pontos percentuais em relação à $6^{a}$ série. Já o segundo tipo de erro mencionado esteve presente como obstáculo na $5^{\mathrm{a}}$ série, com índice de $23,81 \%$, e na $6^{a}$ série com índice de $36 \%$; sendo que na $7^{\text {a }}$ série sua incidência não se configurou como obstáculo, retornado a cena entre $33,33 \%$ dos estudantes da $8^{\mathrm{a}}$ série.

Uma inferência que pode ser feita a esse respeito advém do fato de geralmente se deixar a cargo dos estudantes o estabelecimento das relações entre o aprendizado atual e o que já foi visto por eles em séries anteriores. Sendo assim, qualquer tipo de retomada ou revisão fica a cargo dos próprios estudantes, pois os professores tendem a "lavar as mãos" geralmente argumentando que eles "já deveriam ter aprendido isto".

\section{Considerações Finais}

Pelos resultados desta pesquisa podemos dizer que se um conteúdo matemático não for bem assimilado pode se constituir como um obstáculo didático que se propaga pelas séries escolares posteriores; assim, uma vez estabelecido um obstáculo didático coletivo, dificilmente este será superado pelos estudantes sem a intervenção do professor de forma sistemática. Essas constatações vêm contribuir para reforçar a teoria principalmente a teoria piagetiana - de que cada indivíduo tem um ritmo próprio de aprendizagem, acarretando como consequência que não podemos ensinar tudo a todos no mesmo espaço de tempo. Por sua vez, isto nos impõe, como professores de Matemática, o compromisso de buscar suprir as lacunas de conhecimento dos nossos alunos na série em que estes se encontram, ao invés de agirmos, como geralmente fazemos, ignorando suas lacunas, mesmo detectadas, sob o argumento de que "são assuntos das séries anteriores que todos têm obrigação de saber".

Curiosamente, talvez até sem perceber, em geral reproduzimos o discurso e as atitudes de nossos antigos professores, em termos de erros e obstáculos, desconsiderando o caráter formativo destes no contexto pedagógico do conteúdo matemático. Consciente ou inconscientemente, assumimos tal postura certamente por não saber auxiliar nossos alunos 
a lidar com "seus erros". Seja qual for a "justificativa" ou sejam quais forem as razões para tanto, o fato marcante é que quer a nossa experiência de estudantes quer a nossa formação docente inicial não nos propiciam adquirir conhecimentos para lidar com tais questões; o que configura, sem dúvida, um obstáculo profissional e institucional para a formação de professores do ponto de vista da atribuição de sentido pedagógico aos conteúdos matemáticos.

A pesquisa realizada mostrou, ainda, uma variedade de erros que dificilmente serão relacionados pelos professores, tal como no estudo descrito por Pochulu (2005), baseado na perspectiva docente, justamente em relação com a nossa que teve como fonte as respostas dos estudantes. E como legado, partindo do princípio de que a finalidade do sistema educacional é a aprendizagem efetiva do alunado e que o professor é o agente do sistema que lida mais diretamente com o beneficiário final, estudar os erros dos estudantes é estudar, indiretamente, alguns de nossos próprios erros - como professores de Matemática neste caso - e os erros do sistema em si, tendo em vista a relação existente entre os erros, os obstáculos didáticos e a concepção de avaliação adotada.

Algumas interrogações emergem deste estudo para nos lembrar que ele não é definitivo nem está completo, mas apenas iniciado, pois se torna importante investigar para conhecer outros aspectos que não puderam ainda ser contemplados, a saber: quais são e como se comportam ao longo das séries do ensino fundamental os obstáculos didáticos no âmbito de outras disciplinas? Os termos pelos quais a porcentagem de $20 \%$ utilizada como valor arbitrado para diferenciar 'erros' de 'obstáculos' pode ser evidenciada como relevante e significativa? Que outras variáveis deveriam ser consideradas para determinação de um percentual ou índice de maior propriedade? Em que termos nossas aulas de Matemática e avaliações contribuem para o estabelecimento ou a superação de obstáculos didáticos? Que peso ou influência os obstáculos: epistemológicos, metodológicos, linguísticos e emocionais, têm na formação tanto dos obstáculos didáticos coletivos quanto dos obstáculos didáticos individuais?

Esperamos, pois, que as questões por nós apresentadas possam inspirar outras pesquisas nas mais variadas disciplinas escolares e serem úteis para corrigir possíveis e variados erros sempre cometidos em âmbito escolar. 
ALMOUlOUd, A. S. A Geometria na Escola Básica: que espaço e forma têm hoje? < http://www.ufpel.tche.br/ufpel.tche.br/clmd/bvm/ detalhe_livro.php?id_livro=395 > . Acesso em 18/01/06.

BACHELARD, G. A Formação do Espírito Científico: contribuições para a psicanálise do conhecimento. Trad. de Estela dos Santos Abreu. Rio de Janeiro: Contraponto, 1996.

BITTENCOURT, J. Obstáculos epistemológicos e a pesquisa em Didática da Matemática. Revista Educação Matemática, Ano 5, n. 6, maio de 1998.

CURY, H. N. Retrospectiva histórica e perspectivas atuais da análise de erros em Educação Matemática. Zetetiké, v. 3, n. 4, 1995. p 39-50

DEPRESBITERES, L. O desafio da Avaliação da Aprendizagem: dos fundamentos a uma proposta inovadora. São Paulo: EPU, 1989.

GUSMÃO, T. C. R. S. Do erro construtivista ao erro epistemológico: um espaço para as emoções. Bolema, Ano 13, n. 14, 2000. p. 51-65

LUCKESI, C. C. Avaliação da Aprendizagem Escolar. São Paulo: Cortez, 1995.

PAIS, L. C. Didática da Matemática: uma influência francesa. $2^{\text {a }}$ Ed. Belo Horizonte: Autêntica, 2002.

PINTO, N. B. O Erro como Estratégia Didática: Estudo do erro no ensino da matemática elementar. Campinas: Papirus, 2000.

POCHULU, M. D. Análisis y Categorización de errores en el aprendizaje de la matemática en alumnos que ingresan a la univrsidad. Revista Iberoamericana de Educación, 2005.

ROMÃO, J. E. Avaliação Dialógica: desafios e perspectivas. São Paulo: Cortez, 1998.

VASCONCELlOS, C. dos S. Avaliação: Concepções DialéticoLibertadora do Processo de Avaliação Escolar. São Paulo: Libertad Centro de Formação e Assessoria Pedagógica, 1998. 